\title{
RESEARCH AND DISCUSSION OVER SEISMIC PERFORMANCE OF MODULAR STRUCTURE
}

\author{
Xu Zhong * Aoyi Chen ** Zhihua Chen* Yujie Yu * \\ * Department of Civil Engineering, Tianjin University, Tianjin, China \\ e-mails: 15122809761@163.com zhchen@tju.edu.cn yujietju@163.com \\ ** Tianjin Architecture Design Institute, Tianjin, China \\ e-mails: chenaoyi@tadi.net.cn
}

\begin{abstract}
Modular structure is a new type of steel building with special construction to shorten the construction period and bring other benefits. Some studies on seismic performance of modular structures were introduced. In order to meet much higher seismic requirements with less steel usage, a new type of pretensioned modular frame was proposed, which can develop a more rigid connection between modules. A quasi-static loading test was performed on a full-scale pretension assembled framed modular system, which demonstrated seismic performance of modular connection can be improved through an effective connection. Finally, some technical proposals have been discussed in structural arrangement, calculation method as well as lateral resistant system.
\end{abstract}

Keywords: modular structure, aseismic performance, pretensioned modular frame, seismic design method.

\section{INTRODUCTION}

Modular structures are usually divided into single rooms or several 3D building spaces as their basic construction units. A modular unit will be manufactured in factories, containing columns, beams, walls, ceiling, floor even as well as the pipelines and furniture. When these units are transported to the site, they will be assembled into a complete modular structure.

Due to the special construction method of modular structures, the modular units can be processed as the foundation is constructed on site, which means construction time will be shortened and the quality of structure can be improved in a controlled environment.

In some publications about design of modular structures ${ }^{[1]}$, they tend to only involve wind loads and eccentric load led by manufacture error when they consider the lateral resistance, but the requirements related to seismic design are very limited.

C.D. Annan made pseudo-static tests ${ }^{[2-3]}$ on the seismic performance of modular braced structure (MBS) compared with similar configured regular-braced steel frame, whose result showed the vertical connection will play a significant role.

Sung-Gul Hong ${ }^{[4]}$ put forward a modular system with double skin steel panels instead of concrete core walls and then conducted full-scale experiments and FEM analysis to study its ductility and energy dissipation, showing lightweight steel panels could be a good supplement for seismic performance. Vinicius Aguiar de Souza ${ }^{[5]}$ adopted a shaking table test on a scaled model of seven-storey container building to calibrate a model to predict dynamic properties.

Domestic relative study began with the container buildings, which could be seen as primary form of modular buildings. Lu Ye et al ${ }^{[6]}$ simplified took corrugated panel into a crossed brace. Then the simplified model was used into achieve a structural design considering many load cases which includes earthquake response spectrum. 
Zhang Pengfei from Tianjin University applied the traditional seismic design method to a composite structure composed of modules and steel frame based on a simplification of joints between modules or module and traditional steel frame ${ }^{[7]}$. Qu Kexin also accomplished static performance study, dynamic analysis and pushover analysis of one four-story building considering different rigidity of connection ${ }^{[8]}$.

From the above review, the simplification methods may tend to be dependent on the specified measure used to provide the lateral stiffness and energy dissipation. In terms of modular construction, the seismic performance of a modular structure can largely depend on the connections between modules.

\section{SEISMIC PERFORMANCE OF A NEW PRETENSIONED MODULAR FRAME}

\subsection{A new pretensioned inter-modular connection}

The forms of connection between modules can be greatly variable according to different load-bearing patterns as well as the position of connections. Typical types of inter-modular connections (see Figure la $\sim$ ) involve welding connection, corner fittings, short box-shaped or H-shaped segment and end-plate bolted connection.
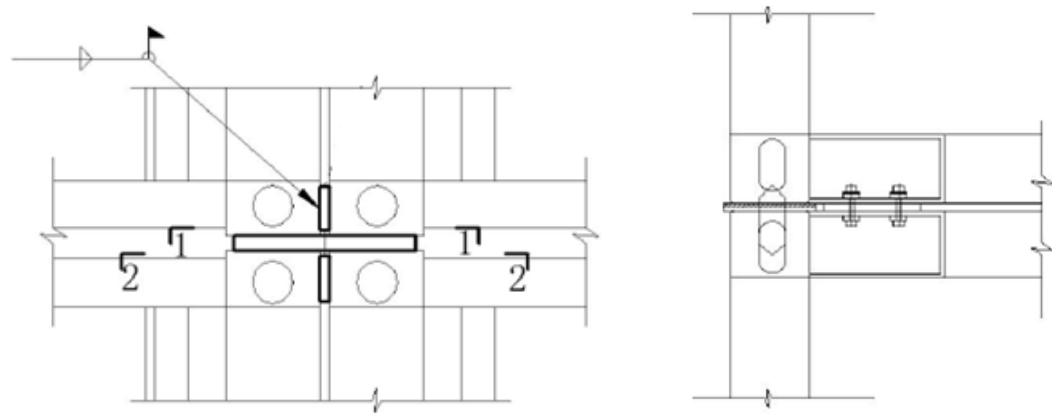

(a) welding connection between modules through pad (b) corner fittings used for connecting modules

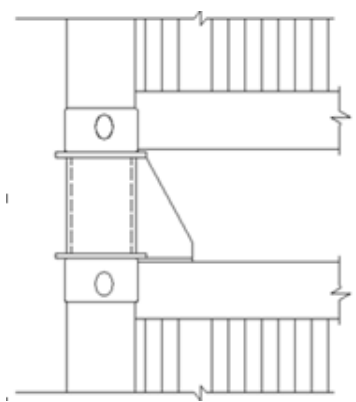

(c) connection by short segment between beams

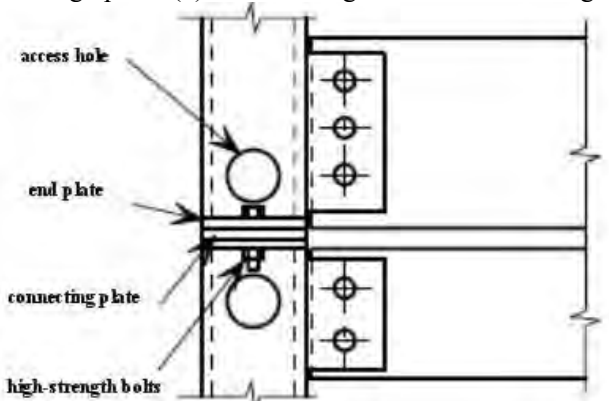

(d) end plate bolted connection in modular structure

Fig. 1 Typical inter-modular connections

Since traditional joints are initially used in container buildings and then adapted for modules mainly considering the simplicity of assembly. However, if a modular structure is introduced in high-rise building or structures in high seismic intensity area, the above connections may be unable to bring enough safety and stiffness of the whole structures. At the same time, larger cross section will be needed for higher lateral resistance, which also leads to a considerable steel usage.

Now a new creative pretensioned inter-modular connection was also applied in modular structure to achieve much higher seismic requirements and lower the steel usage to a rational level. The configuration of such a new connection is shown below (see Figure 2) where rectangular concrete filled steel tubes (CFST) were used for corner columns, whose end has a seal plate with stiffeners and holes spaced for 
pre-stressed strands vertically connecting modular columns, a shear block is set at one column end with the encased hole in the other section to resist shear force, and some connectors were used to fix the steel strands. Sometimes plugin bars were installed to prevent the concrete from crushing as well as ensure the ductility.

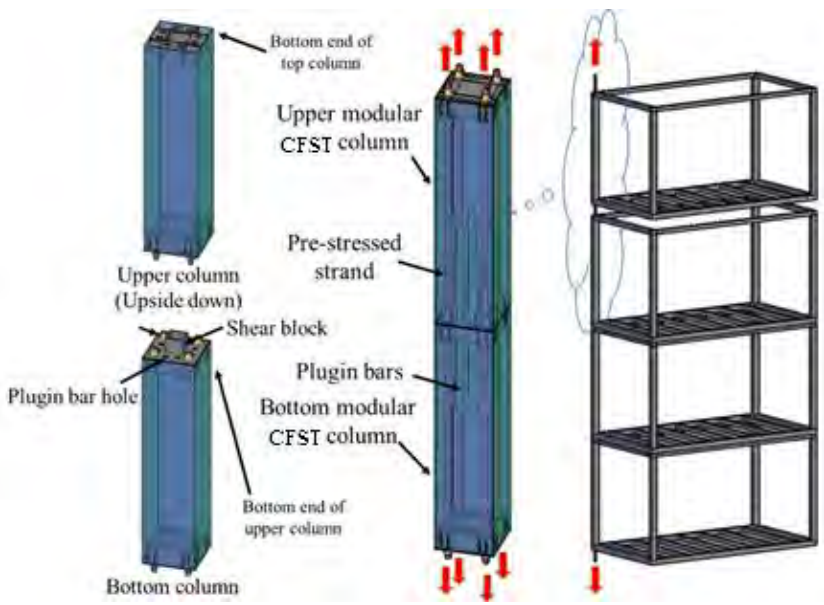

Fig. 2 Pretensioned inter-modular connection

\subsection{The testing plan}

The full-scale quasi-tests were designed to verify the seismic performance of a nine-story modular experimental building and the specimen was selected as the lowest two-story modules $(3.6 \mathrm{~m} \times 4.5 \mathrm{~m} \times 3.0$ $\mathrm{m} /$ Width $\times$ Length $\times$ Height, shown in Fig.3a ) with nearly identical member dimensions (see Table 1) except that floor flab was equivalent to diagonal braces with in-plane stiffness. The details of connection were shown in Fig. 3, where holes at four corners were passed through by strands and intermediate anchorages were placed at every cross section to apply pretension.

Table 1. Member dimensions and materials

\begin{tabular}{ccc}
\hline Member & Material & $\begin{array}{c}\text { Dimension } \\
(\mathrm{mm})\end{array}$ \\
\hline Modular column & $\begin{array}{c}\text { Concrete filled steel tube } \\
(\mathrm{Q} 345 \mathrm{~B} / \mathrm{C} 40)\end{array}$ & $\square 200 \times 200 \times 8$ \\
Modular beams & Q345B & $\mathrm{H} 170 \times 90 \times 8 \times 5$ \\
Longer Ceiling beam & Steel encased concrete $(\mathrm{Q} 345 \mathrm{~B} / \mathrm{C} 40)$ & $200 \times 300$ \\
pretension strand & 1860 grade & $\varphi 21.6$ \\
plugin bars & HRB400 & $28.0 \quad$ (diameter $)$ \\
\hline
\end{tabular}

The pretension level was controlled at $0.4 f_{p t k}$ and the maximum tension force applied at each column is $800 \mathrm{kN}$ which provided almost 0.4 axial compression ratio. The $500 \mathrm{t}$ actuator was arranged between the midpoint of the width of the side beam and reaction wall and the load frame was placed at the ceiling level of upper module to ensure a harmonious horizontal displacement (see Fig 3b).

The earthquake action was analyzed by mode-superposition response spectrum method and the seismic reactions and the applied loads were determined based on the equivalent base shear method and the seismic code of China ${ }^{[9-10]}$. Three earthquake levels were considered when the load was respectively taken as $46 \mathrm{kN}\left(\mathrm{F}_{\mathrm{E}}\right.$, frequently occurring earthquakes), $138 \mathrm{kN}\left(3 \mathrm{~F}_{\mathrm{E}}\right)$ and $230 \mathrm{kN}\left(5 \mathrm{~F}_{\mathrm{E}}\right)$. Eventually, the loading scheme was designed as Fig $3 \mathrm{c}$. 
In order to study the load-displacement curve of the whole frame under earthquake, six displacement meters (D1 D4,D9,D10) were installed at the ceiling level and basement, and four displacement meters (D5 D8) were used to measure the connections openings of. The measure plan was recorded in Fig 3d.

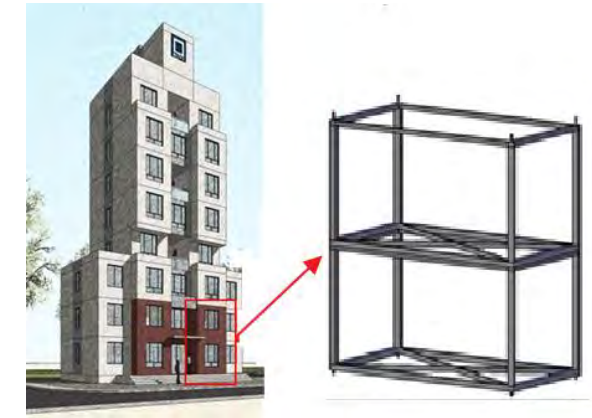

(a) Full-scale two-story modules

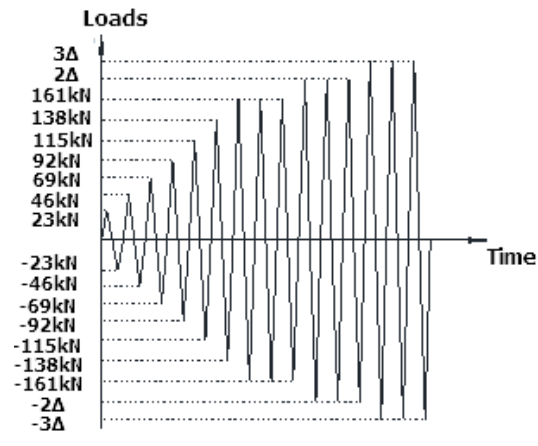

(c) Loading scheme

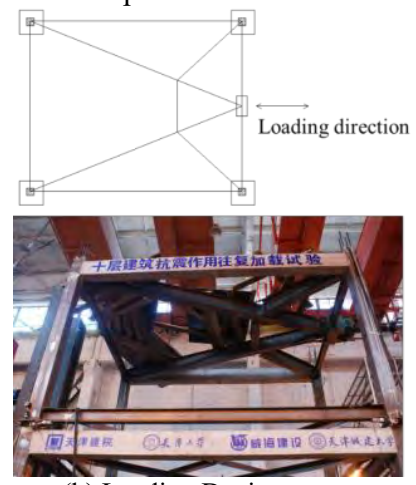

(b) Loading Device

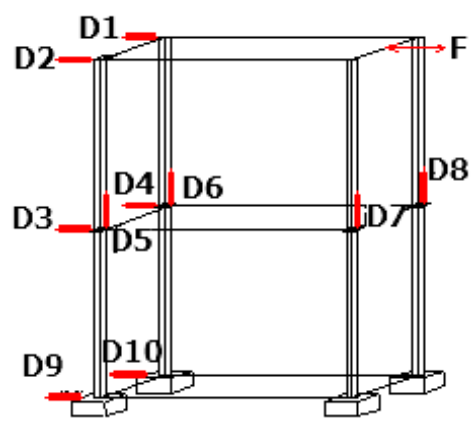

(d)Measuring plan

Fig 3 The quasi-static test

\subsection{The results and analysis}

The pretensioned frame modules experienced a long elastic stage before the earthquake response approached $3 \mathrm{~F}_{\mathrm{E}}(138 \mathrm{kN})$, and the yielding started at the displacement of $68.4 \mathrm{~mm}(\Delta)$ with concrete cracking sounds and slight ashes falling from the ceiling beam. Afterwards, the applied load was controlled by displacement, as the amplitude and repeated cycles increased, the cracking sounds became more frequent and the ceiling beams removed off column flanges, moreover, slip also occurred to strands and plugin bars. Meanwhile the increasing speed tended to slow down and even the obvious reduction of strength happened when the drift reached $3 \Delta$. Finally, the ultimate applied load dropped to $173 \mathrm{kN}(70 \%$ of peak strength) and the test stopped, when apparent inclination of modular column remained until the unload completed. The failure behavior along with load-displacement relation curve was shown in Fig 4.

The Inter-story drifts under different seismic levels were recorded in the below table (Table 2) and it could be concluded that the lateral stiffness of such new system satisfied the limit requirement at small earthquake level(1/250) as well as medium earthquake (1/100), furthermore,the deformation would increase to a large extent (beyond 1/50) but without visible structural damage when earthquake went almost destructive. The difference of deformation may be explained by the changes of gap opening between upper and bottom modules (shown in Fig 5), representing the separation of beams from column and the slip of pretensioned strand.

During the early stage, the strands could prevent the modules from division and ensured superior strength and stiffness, but would gradually lose load transferring capacity after concrete crushed with 
larger openings. However, the strands also improved the bonding effect that the steel tube was prevented from local buckling and in turn confined the concrete to obtain higher compression strength, which also brought economic benefits through saving steel usage. Generally, the pretensioned connection improve the aseismic performance and ductility of modular structure under more intensive earthquake, which demonstrated the effective connection form played a significant role in aseismic performance of modular system.

Table 2 Inter-story drift of the pretensioned modular frame

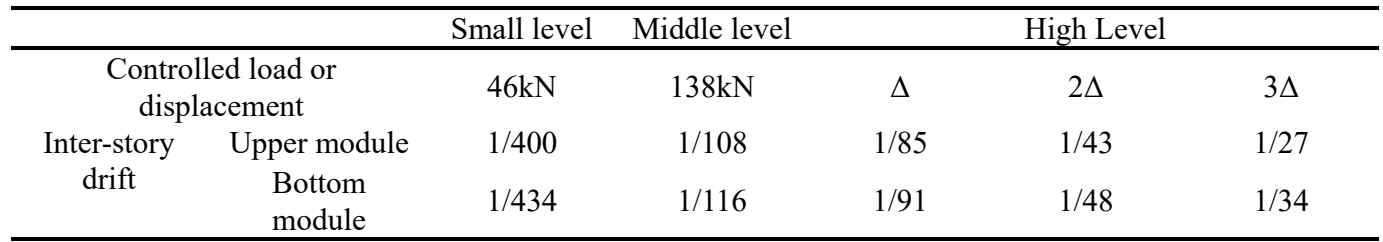

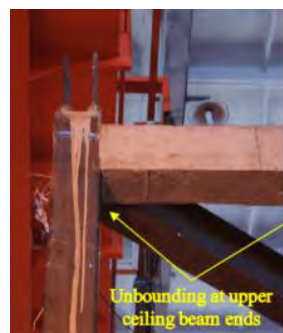

(a) Upper ceiling beam failure

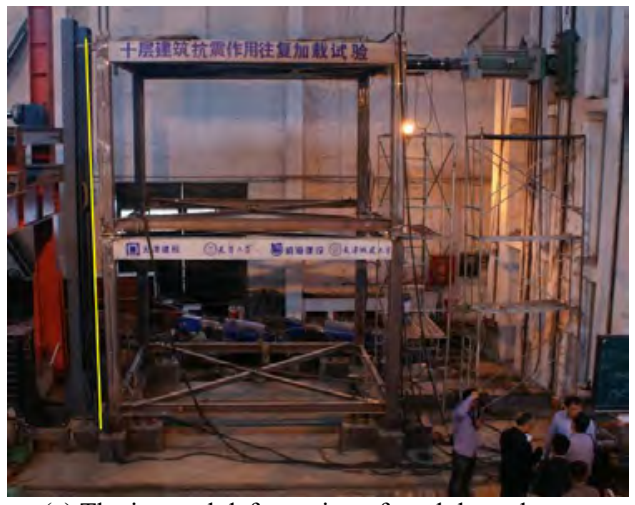

(c) The integral deformation of modular column

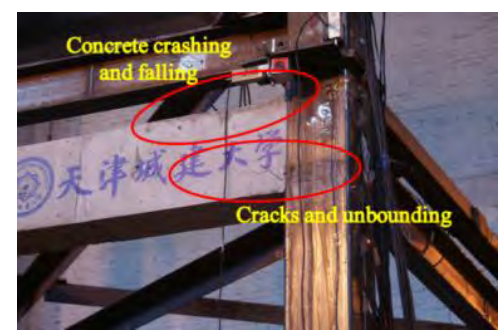

(b) Bottom ceiling beam failure

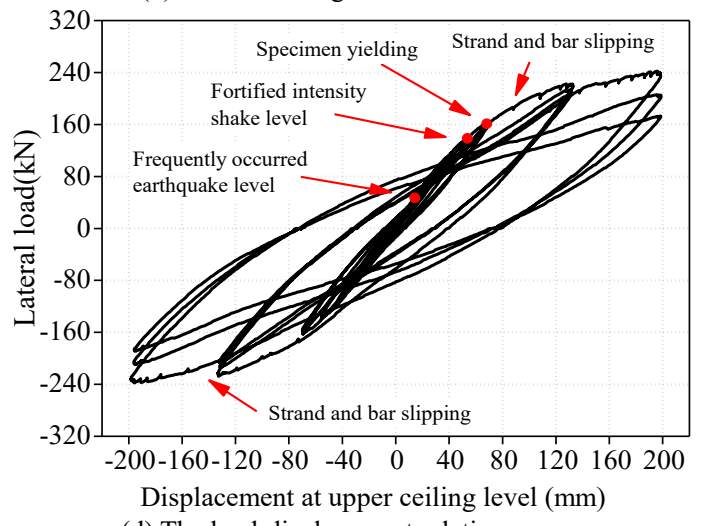

(d) The load-displacement relation curve

Fig 4 Primary results of the experiment

\section{FURTHER DISCUSSION OVER SEISMIC DESIGN OF MODULAR STRUCTURE}

There has been a long history of modular structure in western countries, however, it has come to China since 10 years ago. In China, many cities are located in the earthquake-prone zones, therefore, seismic performance will be an inevitable part in the structural design, which could be quite different from some western countries. It would be a great challenge for us to prompt modular construction in high-rise buildings. In terms of seismic design method, it deserves to be focused in the following three different respects: 


\section{(1) Structural arrangement: flexibility versus standardization}

The basic principle of simplicity, regularity and symmetry is still appropriate for modular structure. Modules are usually made into rectangular forms instead of arbitrary geometric shapes to make mass production and shorter construction period. On the contrary, when it comes to flexible plane layout, more complex modular units and connections will be used,which leads to difficulty in manufacture . What's more, when the modules are not arranged in a correct way, the torsional response will be increased for modular structure subjected to bidirectional earthquake motion.

\section{(2) Calculation method: how to select and evaluate connections}

The current method is actually based on traditional codes of seismic design or steel structure after the joints are simplified. However, the relative research on joint behavior and simplified design method of modular structure is relatively fragmented, which doesn't match the diversity of joints used for modules. As a result, it will be necessary to summarize load capacity, effective stiffness and energy dissipation of connections and provide the rules to select suitable connection as well as approximate calculation method for modular building with different height or different seismic requirement.

\section{(3) Lateral resistant system: how much action modules have to resist}

As for low rise modular buildings free of seismic design, it will be reliable only by using the stiffness of modular units. However, with the height or the intensity of earthquake increases, it can be hard to accomplish without additional lateral resistant system. Considering the unique connections used for modular buildings, the lateral system is supposed to take all horizontal force and modules are only required to burden the weight and live load.

In fact, it will be necessary to study how modules and the additional lateral system transfer seismic action and improve the structural behavior of modules at the same time. On the one hand, the modular units are required to perform well as the second defense line under earthquake and avoid the collapse of modules under severe earthquake; on the other hand, the proportion of additional lateral system should be controlled to improve economy of modular structures.

\section{ACKNOWLEDGEMENT}

This research was sponsored by the National Key Research and Development Program of China (Grant NO. 2017YFC0703800) and the National Science Foundation of Tianjin (Grant NO. 17JCZDJC38900).

\section{REFERENCES}

[1] R. M. Lawson, J. Richards, "Modular design for high-rise buildings", Procedings of The Institution of Civil Engineers-Strucures and Buildings, 163(3): 151-164, 2010.

[2] Annan C D, Youssef M A, El Naggar M H, "Experimental evaluation of the seismic performance of modular steel-braced frames”, Engineering Structures, 31(7): 1435-1446, 2009.

[3] Annan C D, M. A. Youssef, M. H. El Naggar, "Seismic Vulnerability Assessment of Modular Steel Buildings", Journal of Earthquake Engineering, 13(8): 1065-1088, 2009.

[4] Sung-Gul Hong, Bong-Ho Cho, "Behavior of framed modular building system with double skin steel panels", Journal of Constructional Steel Research, 67(6): 936-946, 2011.

[5] Souza V.A.D, Kirkayak L, Suzuki K, et al, "Experimental and numerical analysis of container stack dynamics using a scaled model test". Ocean Engineering, 39(1):24-42, 2012.

[6] Lu Ye, Liu Qing, Chen Yulong, Luo Shishun, "Structural Design Technology of Container Buildings", Industrial Construction, 44(2),130-136, 2014.

[7] Zhang Pengfei, Zhang Xizhi, Liu Jiadi, Chen Zhihua, "Structural design and analysis of multistorey steel structure module and steel frame composite structures", Building Structure, 46 (10): 100, 2016. 
[8] Qu Kexin, "Study on steel structural system in modular buildings", Tianjin University, 2013.

[9] UBC, "Structural engineering design provisions". In: Uniform building code, International conference of building officials, 1997.

[10] Ministry of Housing and Urban-Rural Development People's Republic of China, GB50011-2010 "Code for Seismic Design of Building”, China Architecture Building Press, Beijing, 2010. 